\title{
Armazenamento de frutos de quiabo embalados com filme de PVC em condição ambiente
}

\author{
Wagner F da Mota ${ }^{1}$; Fernando Luiz Finger²; Paulo Roberto Cecon²; Derly José H da Silva² ${ }^{2}$ Paulo César \\ Corrêa ${ }^{2}$; Lúcia P Firme²; Ludmila L de M Neves ${ }^{2}$ \\ ${ }^{1}$ Unimontes, Dep ${ }^{\text {to }}$. Ciências Agrárias, 39440-000 Janaúba-MG; ${ }^{2}$ UFV, 36571-000 Viçosa-MG; E-mail: wagner.mota@ unimontes.br
}

\begin{abstract}
RESUMO
O presente trabalho objetivou avaliar a influência do filme de PVC durante o armazenamento, em condição ambiente, de frutos de quatro cultivares de quiabo para consumo in natura. O experimento foi organizado segundo delineamento experimental em blocos casualizados, em esquema de parcelas subdivididas, tendo nas parcelas um fatorial $2 \times 4$, ou seja, embalagens sem e com PVC e quatro cultivares (Amarelinho, Red Velvet, Star of David, Mammoth Spinless), e nas subparcelas os seis períodos de amostragem com quatro blocos. As características avaliadas foram: massa fresca, teor relativo de água, teor de vitamina $\mathrm{C}$, teor de clorofila total e análise visual do escurecimento. O uso do PVC proporcionou menor perda de massa fresca e maior teor relativo de água ao longo do armazenamento para todas as cultivares estudadas em relação às não embaladas com o filme. As menores perdas de massa fresca foram verificadas nas cvs. Amarelinho e Star of David sem e com PVC, respectivamente. Os frutos das cvs. Red Velvet e Star of David, embalados com PVC, apresentaram menores perdas no teor de vitamina C. Foi observado que a cv. Mammoth Spinless manteve maior teor de clorofila. Observou-se, de maneira geral, maior incidência de escurecimento nos frutos armazenados sem PVC. Verificou-se que de toda as cultivares estudadas o que manifestou melhor conservação com relação ao escurecimento foi o Red Velvet.
\end{abstract}

Palavras-chave: Abelmoschus esculentus, armazenamento, vitamina C.

\begin{abstract}
Shelf life of four cultivars of okra covered with PVC film at room temperature
\end{abstract}

The present work evaluated the influence of PVC film on the postharvest shelf life of four cultivars of okra stored at room temperature. The experiment was arranged in random blocks, in sub split parcels, where the parcels were a factorial $2 \times 4$, with and without PVC film and the cvs. Amarelinho, Red Velvet, Star of David and Mammoth Spinless, and the subparcels the six sample time with four blocks. The characteristics evaluated were: percentage of weight loss, relative water content, total chlorophyll and chlorophyll a and $\mathrm{b}$, content of vitamin C, visual browning. The PVC was efficient in controlling the weight loss and retained the water content through storage. The lowest losses were observed for the cvs. Amarelinho and Star of David, without and with PVC, respectively. There was higher retention of vitamin C in the fruits wrapped with PVC and the cvs. Red Velvet and Star of David kept higher content of it. In general, the cv. Mammoth Spinless kept higher content of chlorophyll. The higher incidence of browning was in fruits stored without PVC. The Red Velvet had better shelf life due to lower browning.

Keywords: Abelmoschus esculentus, storage, vitamin C.

(Recebido para publicação em 12 de julho de 2005; aceito em 24 de abril de 2006)

$\mathrm{O}$ quiabeiro

(Abelmoschus esculentus L. Moench) é uma hortaliça da família Malvácea cultivada na África, Ásia, Estados Unidos, Austrália e Brasil (Duzyaman, 1997). No Brasil, sua popularidade está aumentando, pois apresenta algumas características desejáveis, como ciclo rápido, baixo custo de implantação e condução, resistência a pragas e alto valor nutritivo (Mota et al., 2000).

O fruto do quiabeiro é constituído por $89,9 \%$ de água do total do seu peso fresco (Mota et al., 2000; Duzyaman, 1997). Desta forma, o quiabo se comporta como fruto perecível, quando exposto a condições ambientais com baixa umidade relativa e alta temperatura, pois tais condições propiciam a ocorrência de murcha ocasionada pela intensa atividade respiratória e elevada perda de água (Scheer, 1994). Desta forma, o quiabo é um produto hortícola perecível com período de conservação póscolheita extremamente curto, principalmente em condições de armazenamento sob temperaturas altas e baixa umidade relativa, pois estas condições aceleram a perda de água, depreciando o valor comercial dos frutos para o consumo in natura, sendo o maior problema na conservação de quiabo, além de reduzir o teor de sólidos solúveis e de vitamina $\mathrm{C}$ (Della-Justina, 1998).

A manutenção da qualidade e consequentemente a extensão pós-colheita do quiabo, pode ser obtida com o uso de atmosfera modificada e/ou controlada (Brosnan \& Sun, 2001). A atmosfera modificada está continuamente se tornando importante como trata- mento para prolongar o período de armazenagem de produtos perecíveis reduzindo perdas e mantendo a qualidade. Esta técnica reduz a atividade respiratória e aumenta a umidade relativa, dimunuindo, assim, a perda de água por transpiração, e conseqüentemente o murchamento (Amarante et al., 2001). Muitos filmes plásticos com diferentes permeabilidades a gases são empregados em frutos e hortaliças, tais como o polietileno de baixa densidade (PEBD) e o cloreto de polivinila (PVC) (Zagory \& Kader, 1988).

O presente experimento teve como objetivo avaliar a influência do filme plástico de PVC sobre a conservação pós-colheita de quatro cultivares de quiabo para consumo in natura armazenados em condições ambientes. 


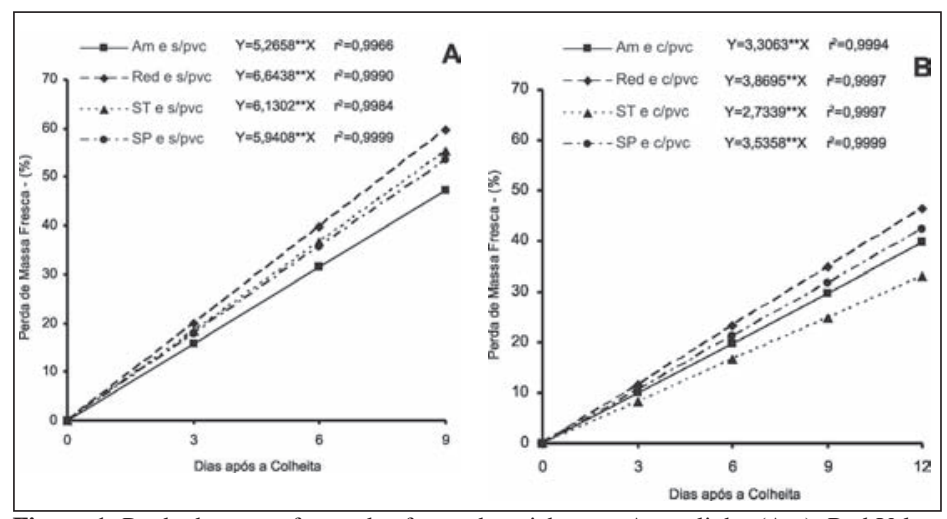

Figura 1. Perda de massa fresca dos frutos de quiabo cvs. Amarelinho (Am), Red Velvet (Red), Star of David (ST) e Mammoth Spinless (SP) armazenados e embalados sem (A) e com (B) PVC. Janaúba, Unimontes, 2001.

\section{MATERIAL E MÉTODOS}

Os frutos de quiabo das cvs. Amarelinho, Red Velvet, Star of David e Mammoth Spinless foram colhidos, no estádio de colheita comercial, na Horta de Pesquisa da Universidade Federal de Viçosa (UFV), em Viçosa, MG, no período de março a maio de 2001. Após a colheita os frutos foram acondicionados em caixas plásticas e transportados para o Laboratório de Pós-Colheita, do Departamento de Fitotecnia.

Os frutos das quatro cultivares foram selecionados, posteriormente foram divididos em dois lotes, em seguida a metade foi armazenada em bandejas de poliestireno expandido com PVC esticável e auto-aderente (com permeabilidade a $\mathrm{O}_{2}$, e $\mathrm{CO}_{2}$ de 620 e $4263 \mathrm{~cm}^{3} \mathrm{~m}^{2} \mathrm{dia}^{-1}$, respectivamente, e espessura de $12 \mathrm{~mm}$ ) a outra metade foi armazenada em bandejas sem PVC. Logo depois os dois lotes foram armazenados em condições ambientes $\left(22 \pm 2^{\circ} \mathrm{C}\right.$ e $80 \pm 5 \%$ de umidade relativa). Antes das análises físicas e químicas, o experimento foi organizado segundo delineamento experimental em blocos casualizados, em um esquema de parcelas subdivididas, tendo nas parcelas um fatorial $2 \times 4$, ou seja embalagens sem e com PVC e as quatro cvs. Amarelinho, Red Velvet, Star of David e Mammoth Spinless, e nas subparcelas os seis períodos de amostragem com quatro blocos, sendo a unidade experi- mental constituída por quatro frutos. As características físicas e químicas foram avaliadas em intervalos de 3 dias. Para o cálculo da massa fresca do fruto, a diferença de massa fresca entre as avaliações foi acumulada durante a evolução do experiment. Assim, o resultado de perda de matéria fresca em relação à massa inicial do fruto foi expresso em porcentagem.

$$
\phi=\frac{F-W}{T-W} X 100
$$

O teor relativo de água foi determinado conforme metodologia descrita por Catsky (1974),

com o emprego da equação citada por Weatherley (1950):

Em que F é o teor relativo de água; $\mathrm{F}$, massa da matéria fresca; $\mathrm{W}$, massa da matéria seca; e T, massa túrgida. Foram retirados discos de $7 \mathrm{~mm}$ de diâmetro do pericarpo do quiabo e pesados. Os discos foram incluídos em espumas saturadas de água por 7 horas (tempo necessário para estabilização da massa) e pesados, obtendo-se a massa da matéria túrgida. Em seguida, foi obtida a $70^{\circ} \mathrm{C}$ até massa constante.

$\mathrm{O}$ teor de vitamina $\mathrm{C}$ foi determinado segundo técnica recomendada pelo Instituto Adolfo Lutz (1985). Amostras de $5 \mathrm{~g}$ de massa fresca do fruto foram trituradas em $100 \mathrm{~mL}$ de água destilada com o auxílio de um homogeneizador de tecidos. Em seguida, foi adicionado à mistura $20 \mathrm{~mL}$ de ácido sulfúrico (a massa seca por secagem em estufa a
$20 \%$ ), filtrando-se posteriormente a solução. Foi adicionado ao filtrado, 1 $\mathrm{mL}$ de iodeto de potássio a $10 \%$ e $5 \mathrm{~mL}$ da solução de amido a $1 \%$, que foi seguido por titulação com solução de iodato de potássio a $0,01 \mathrm{~N}$ até coloração azul. O teor de clorofila total foi determinado a partir da homogeneização de $3 \mathrm{~g}$ de massa fresca da parte mediana dos frutos, em $10 \mathrm{mg}$ de sulfato de magnésio e $30 \mathrm{ml}$ de acetona $80 \%$ (v/ v). A suspensão foi filtrada, aferida em um balão volumétrico de $50 \mathrm{~mL}$. O teor de clorofila total foi determinado espectrofotometricamente pelo método de Arnon (1949) nos comprimentos de onda de 645 e 663 nm. A presença de manchas de descoloração foram avaliadas utilizando notas subjetivas: $0=\mathrm{au}$ sência de manchas escuras; $1=$ levemente escurecidos; $2=$ moderadamente escurecidos; $3=$ extremamente escurecidos; 4= completamente escurecidos com mais de $50 \%$ de manchas escuras na superfície do fruto.

Os dados foram interpretados por meio de análise de variância e de regressão. As médias dos fatores qualitativos foram comparadas, utilizando-se o teste de Tukey ao nível de $5 \%$ de probabilidade. Para os fatores quantitativos, os modelos foram escolhidos com base na significância dos coeficientes de regressão, utilizando-se o teste de t, de Student, a $5 \%$ de probabilidade, no coeficiente de determinação e no potencial para explicar o fenômeno biológico.

\section{RESULTADOS E DISCUSSÃO}

Observou-se aumento linear da perda de massa fresca ao longo do período de armazenamento das cultivares (Figura 1). Nos frutos armazenados sem PVC o aumento linear da perda de massa fresca foi da ordem de 5,26; 6,64; 6,13 e $5,94 \%$ por dia nas cvs. Amarelinho, Red Velvet, Star of David e Mammoth Spinless, respectivamente, acumulando ao final de nove dias de armazenamento perdas de 47,34; 59,76; 55, 17 e 53,46\% na mesma ordem (Figura 1A). Nos frutos armazenados com PVC, o aumento diário foi de 3,30; 3,86; 2,73 e 3,53\% nas cvs. Amarelinho, Red Velvet, Star of David e Mammoth Spinless respectivamente, atingindo perdas de 39,6 ; 
46,32; 32,76 e 42,36\% após 12 dias de armazenamento (Figura 1A). Os frutos das quatro cultivares quiabo embalados com PVC apresentaram menor perda de massa fresca durante o armazenamento, alcançando armazenamento por 12 dias (Figura 1B). A embalagem com PVC proporcionou um menor gradiente de pressão de vapor entre a atmosfera interna e a superfície do fruto. Além disso, as condições de atmosfera modificada reduz a concentração de oxigênio em relação a atmosfera normal, diminuindo a respiração e aumentando a conservação pós-colheita.

Verificou-se em ambas as condições (com e sem PVC) que a cv. Red Velvet manifestou maior perda de massa fresca ao longo do armazenamento (Figuras 1A e 1B). Em condição de armazenamento sem PVC, a menor perda de massa fresca foi verificada na cv. Amarelinho enquanto com uso de PVC a menor perda foi na 'Star of David'. Foi verificada por Della-Justina (1998) que o uso de PVC em condições ambientes, na cv. Amarelinho, foi eficiente na redução da perda de massa fresca em relação aos frutos acondicionados sem PVC, prolongando a conservação em 5 dias. Houve redução linear do teor relativo de água, ao longo do período de armazenamento, nos frutos de todas as cultivares armazenados (Figura 2). Observa-se maior teor relativo de água nos frutos embalados com PVC em relação aos embalados sem PVC (Figura 2). A perda diária dos frutos embalados com PVC foi de 1,93\%, atingindo ao final de 12 dias teor relativo de água de $68,31 \%$ (Figura 2). Para os frutos não embalados o teor foi de $64,44 \%$ em um período de nove dias, em consequiência da perda diária de 2,73\% (Figura 2). A redução do teor relativo de água ocorreu simultaneamente com a perda de massa fresca durante o período de armazenagem (Figura 1A e 1B).

A perda diária de vitamina $\mathrm{C} 0,39$ mg $100 \mathrm{~g}^{-1}$ de massa fresca nos frutos armazenados sem PVC, atingindo ao final do período de armazenamento 3,09 mg $100 \mathrm{~g}^{-1}$ de vitamina C (Figura 2). No entanto, nos frutos armazenados com PVC, as perdas foram inferiores com redução diária de $0,24 \mathrm{mg}^{100 \mathrm{~g}^{-1}} \mathrm{e}$ acumulando ao final de 12 dias um teor de

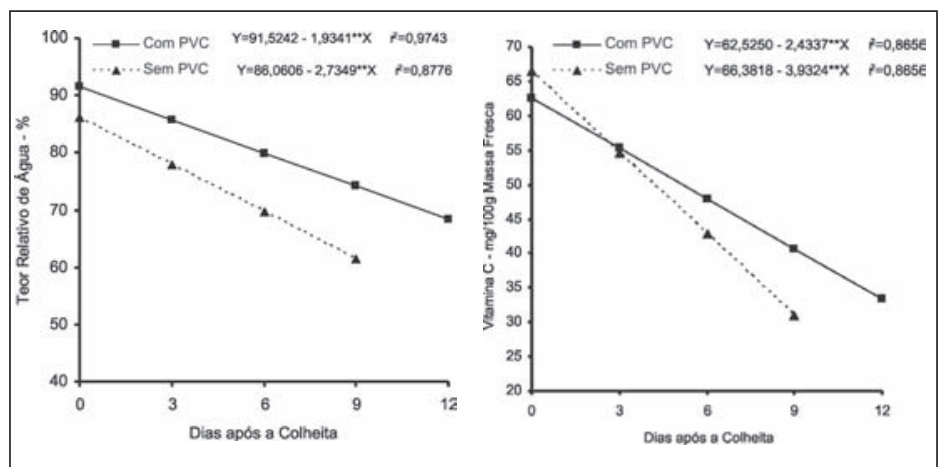

Figura 2. Teor relativo de água e teor de vitamina $\mathrm{C}$ dos frutos de quiabeiro armazenados $\mathrm{e}$ embaladas sem ("\%) e com ( \%) PVC. Janaúba, Unimontes, 2001.

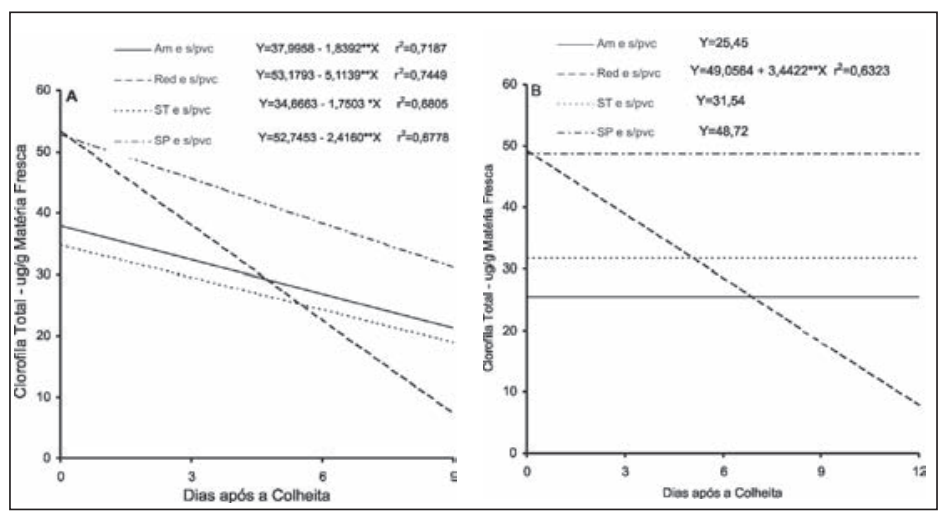

Figura 3. Teor de clorofila total dos frutos de quiabeiro das cvs. Amarelinho (Am), Red Velvet (Red), Star of David (ST) e Mammoth Spinless (SP), armazenados sem (A) e com (B) PVC em condições ambientes, em função dos dias após a colheita. Janaúba, Unimontes, 2001.

3,33 mg $100 \mathrm{~g}^{-1}$ (Figura 2). Esta redução do teor de vitamina C com o avanço do período de armazenamento também foi verificada por Della-Justina (1998). Segundo Lee \& Kader (2000), temperaturas mais elevadas, como as verificadas em condições ambientes, ruduziram os terores de vitamina $\mathrm{C}$.

Houve redução no teor de clorofila total ao longo do período de armazenamento em todas as cultivares armazenadas sem PVC (Figura 3). A taxa de perda diária de clorofila total foi de 1,$83 ; 5,11 ; 1,75$ e 2,41 ug.g ${ }^{-1}$ MF nas cvs. Amarelinho, Red Velvet, Star of David e Mammoth Spinless, respectivamente. Dessa forma, após nove dias de armazenamento seus teores reduziram para 21,52; 7,15; 18.91 e 31,00 ug g ${ }^{-1} \mathrm{MF}$ de clorofila total nas cvs. Amarelinho, Red Velvet, Star of David e Mammoth
Spinless, respectivamente (Figura 3 A). Por outro lado, nos frutos armazenados com PVC, somente a cv. Red Velvet, perdeu clorofila total ao longo do armazenamento (Figura 3B), com perda diária de 3,44 ug g ${ }^{-1} \mathrm{MF}$ de clorofila total. Entretanto, as perdas observadas foram inferiores às verificadas sob condições de armazenamento sem PVC.

A degradação da clorofila em hortaliças não climatéricas, como o quiabo, pode ser uma desvantagem na qualidade, pois as perdas de clorofila são reflexos da senescência (Beaudry, 1999). A degradação da clorofila pode ser mediada por vários processos como a ação da enzima clorofilase, oxidação enzimática ou fotodegradação (Beaudry, 1999). A manutenção da coloração é uma característica importante em todas as fases da cadeia como produção, armazenagem e 
comercialização (Kays, 1991; Kays, 1999). A clorofila é um pigmento afetado pela atmosfera modificada sendo amplamente associada com a qualidade de hortaliças (Lee \& Kader, 2000). Dessa forma, ocorreu, de maneira geral, redução do desverdecimento com o uso da atmosfera modificada.

Os frutos das cvs. Amarelinho e Red Velvet armazenados e embalados com ou sem PVC, mantiveram notas zero, significando ausência de escurecimento (manchas visuais) e ótimo estado de conservação até três dias após a colheita. Della-Justina (1998) verificou que os da cv. Amarelinho, verificou que os frutos da cv. Amarelinho embalados em PVC manifestou-se perfeitos até o segundo dia enquanto nos armazenados sem PVC houve princípio de escurecimento logo no segundo dia após a colheita intensificando-se ao longo do período de armazenamento. Os frutos das cvs. Star of David e Mammoth Spinless evidenciaram escurecimento a partir do terceiro dia após a colheita sem ou com PVC, com notas de 0,50 e 0,25 e 0,25 e 0,18 respectivamente.

Em todas as cultivares estudadas, a cv. Red velvet manifestou maior conservação com ou sem uso de filme polimérico de PVC e 'Star of David' apresentou pior estado de conservação, isso devido aos sintomas no escurecimento que condiciona defeito na qualidade, provavelmente com indução na atividade das enzimas peroxidase e polifenol oxidase (Hammer, 1993; Beaudry, 1999).

O uso da embalagem de PVC reduziu a perda de massa fresca e escurecimento, manutenção de maior teor relativo de água, clorofila total e vitamina $\mathrm{C}$ ao longo do armazenamento. A cv. Star of David manifestou bom estado de conservação com manutenção de maiores teores de vitamina $\mathrm{C}$ e reduzida perda de matéria fresca, em conjunto com a cv. Amarelinho. A cv. Red Velvet, apesar de ter evidenciado boas características de conservação com menor escurecimento e elevados teores de vitamina $\mathrm{C}$, manifestou maior perda de matéria fresca e de clorofila ao longo do armazenamento.

\section{REFERÊNCIAS}

AMARANTE C, BANKS NH, GANESH S. 2001. Relationship between character of skin cover of coated pears and permeance to water vapour and gases. Postharvest Biology and Technology 21: 291-301.

ARNON DI. 1949. Copper enzyme in isolated chloroplasts polyphenoloxidase in Beta vulgaris. Plant Physiology 24: 1-15.

BEAUDRY RM. 1999. Effect of O2 and CO2 partial pressure on selected phenomena affecting fruit and vegetable quality. Postharvest Biology and Technology 15: 293-303.

BROSNAN T, SUN DW. 2001. Precooling techniques and applications for horticultural products - a review. International Journal of Refrigeration 24: 154-170.
CATSKY J. 1974. Water content. In: SLAVIK B (eds). Methods of studying plant water relations. Berlin: Springer-Verlag. p.121-31.

DELLA-JUSTINA ME. 1998. Conservação póscolheita do quiabo, influenciada por idade, dano mecânico, filme de PVC e temperatura. Viçosa: UFV 67p. (Tese mestrado).

DUZYAMAN E. 1997. Okra: botany and horticulture. In: JANICK J. Horticultural Reviews 21: 41-72.

HAMMER FE. 1993. Oxidoreductases. In: NAGODAWITHANA T; REED G.(eds). Enzymes in food processing. San Diego: Academic Press.

INSTITUTO ADOLFO LUTZ. 1985. Normas analíticas do Instituto Adolfo Lutz; métodos químicos e físicos para análises de alimentos. São Paulo. 183p.

KAYS SJ. 1991. Postharvest physiology of perishable plant products. New York: Van Nostrand Reinhold. 453p.

KAYS SJ.1999. Preharvest factors affecting appearance. Postharvest Biology and Technology 15: 233-247.

LEE SK, KADER AA. 2000. Preharvest and postharvest factors influencing vitamin $\mathrm{C}$ content of horticultural crops. Postharvest Biology and Technology 20: 207-220.

MOTA WF; FINGER FL.; CASALI VWD. 2000 Olericultura: Melhoramento Genético do Quiabeiro. Viçosa: UFV. 144p.

SCHEER A. 1994. Reducing the water loss of horticultural and arable products during long term storage. Acta Horticulturae 368: 511-522.

ZAGORY DL, KADER AA. 1988. Modified atmosphere packaging of fresh produce. Food Technology 42: 70-77.

WEATHERLEY PE. 1950. Studies in the water relations of cotton plant. I - The field measurement of water deficits in leaves. New Phytologist 49: 81-97. 